NBER WORKING PAPER SERIES

\title{
SPECIFIC CAPITAL AND TECHNOLOGICAL VARIETY
}

\author{
Boyan Jovanovic \\ Peter L. Rousseau \\ Working Paper 13998 \\ http://www.nber.org/papers/w13998
}

\section{NATIONAL BUREAU OF ECONOMIC RESEARCH \\ 1050 Massachusetts Avenue \\ Cambridge, MA 02138}

May 2008

We thank S. Engerman, A. Hortacsu, D. Neal, and M. Perry for helpful comments, Matthias Kredler for research assistance, and the National Science Foundation and the Marion Eqing Kauffman Foundation for support. The views expressed herein are those of the author(s) and do not necessarily reflect the views of the National Bureau of Economic Research.

NBER working papers are circulated for discussion and comment purposes. They have not been peerreviewed or been subject to the review by the NBER Board of Directors that accompanies official NBER publications.

(C) 2008 by Boyan Jovanovic and Peter L. Rousseau. All rights reserved. Short sections of text, not to exceed two paragraphs, may be quoted without explicit permission provided that full credit, including (C) notice, is given to the source. 
Specific Capital and Technological Variety

Boyan Jovanovic and Peter L. Rousseau

NBER Working Paper No. 13998

May 2008

JEL No. O0,O4

\section{ABSTRACT}

Growth of technological variety offers more scope for the division of labor. And when a division of labor requires some specific training, the technological specificity of human capital grows and, with it, probably the firm specificity of that capital. We build a simple model that captures this observation. The model implies that a rising specialization of human and physical capital raises the rents in the average match between a firm and its human and physical capital. We document that in the last 40 years the firm's share of those rents has also grown, and we use the model to explain why this shift may have taken place.

Boyan Jovanovic

New York University

Department of Economics

19 W. 4th Street, 6th Floor

New York, NY 10012

and NBER

Boyan.Jovanovic@nyu.edu

Peter L. Rousseau

Department of Economics

Vanderbilt University

VU Station B \#351819

2301 Vanderbilt Place

Nashville, TN 37235-1819

and NBER

peter.1.rousseau@vanderbilt.edu 


\title{
Specific Capital and Technological Variety*
}

\author{
Boyan Jovanovic and Peter L. Rousseau ${ }^{\dagger}$ \\ May 2008
}

\begin{abstract}
Growth of technological variety offers more scope for the division of labor. And when a division of labor requires some specific training, the technological specificity of human capital grows and, with it, probably the firm specificity of that capital. We build a simple model that captures this observation. The model implies that a rising specialization of human and physical capital raises the rents in the average match between a firm and its human and physical capital. We document that in the last 40 years the firm's share of those rents has also grown, and we use the model to explain why this shift may have taken place.
\end{abstract}

\section{Introduction}

The division of labor may be limited by the extent of the market as Smith (1776) argued, but it clearly is also limited by the variety of technology. ${ }^{1}$ A world hypothetically populated by trillions of cavemen would, in spite of its large market, probably offer little opportunity for labor to specialize - cavemen could find very few activities to specialize in since stone-age technology comprised very few distinct tasks. And when a division of labor requires some specific training, the technological specificity of human capital is limited by the variety of technology. This likely means that the firm specificity of that capital is limited by the same thing: Technological variety. This paper will model this hypothesis more carefully and use it to understand some recent trends in firms' earnings and stock prices, and in the management premium.

*We thank S. Engerman, A. Hortacsu, D. Neal, and M. Perry for helpful comments, Matthias Kredler for research assistance, and the National Science Foundation and the Kauffman Foundation for support.

${ }^{\dagger}$ Jovanovic: Department of Economics, New York University. Rousseau: Department of Economics, Vanderbilt University.

${ }^{1}$ Technological variety can be (and has been) treated as an endogenous variable that might even be affected by the size of the market. Indeed, the model that we present makes variety endogenous, although not in the standard IO fashion. 
Over the past 35 years, the United States has seen a high rate of growth in the variety of products and in the variety of technologies used to produce them. For the period from 1971 to 2006, for example, the stock of patents grew at an annual rate of 1.9 percent and trademarks grew at 3.9 percent. ${ }^{2}$ Alternatively, patenting flows grew at 3.4 percent and trademarking flows at 8.6 percent per year. The rise in patenting was not a mere increase in duplication (see Kortum and Lerner, 1999), and thus we can be reasonably certain that the number of distinct technologies in use is vastly larger today than it was 40 years ago.

The number of business establishments also grew, though at the slower rate of 1.6 percent per year. ${ }^{3}$ Thus a firm controls an ever smaller fraction of available technologies, and produces an ever smaller fraction of available products. The reason for this is presumably some sort of managerial 'span of control' argument in which a manager cannot efficiently oversee a diverse set of activities. Lucas (1978) models the span of control limitation in terms of a firm's employment in a single production function for a single good. Extensions to many activities are done by Jovanovic (1993) with symmetric products, and Mitchell (2000) where some products suit the firm better than others. Mitchell assumes that a firm loses efficiency when the goods and services that it sells start to differ more and more from its core competence.

A firm's core competence presumably depends on the type of capital - human and physical - that is housed in the firm, and an efficient firm is one that sells goods and services that match well the human capital of its workers. Therefore a firm's efficiency depends on the quality of the match between its workers and the goods and services that it sells. The quality of this match is the focus of our model. We shall assume that the growth of product variety has led to an increase in the dispersion of the quality of the firm-worker match. In other words, that there has been an increase in the firm specificity of human capital. We shall show that such a rise in specificity may explain why over the past thirty-five years

1. Firms' earnings have risen,

2. Tobin's $Q$ and the management premium have risen with no accompanying rise in productivity growth, and

\footnotetext{
${ }^{2}$ To obtain the growth rate of the stock of patents, we start with the total number of "utility" (i.e., invention) patents granted by the U.S. Patent and Trademark Office for 1963-2006 (www.uspto.gov) and the Historical Statistics of the United States (U.S. Bureau of the Census, 1975, series W96, pp. 957-959) for 1790-1962. We then take the cumulative number of patents granted up to 1970 as the starting point for computing growth rates for 1971 to 2006. The number of registered trademarks are from Historical Statistics (series W-107, p. 959) for 1870-1969 and various issues of the Census Bureau's Statistical Abstract of the United States for later years. For trademarks, we use the cumulative number issued from 1870 to 1970 as the starting point for the growth rate calculation.

${ }^{3}$ We build a series for the number of business establishments using various issues of the Statistical Abstract 1980-2003, linearly interpolating between missing values in 1981-84 and 1986-87. We then join this series with the number of business concerns from the Statistical Abstract for 1970-80.
} 
3. Labor turnover has declined, but not managerial turnover.

A summary of the argument.- Our argument runs as follows: Rising specialization of firms and their inputs has forced firms to try harder to find those inputs that suit their needs best. Management has the task of finding the right inputs; its role and its reward have therefore risen. When a firm has its IPO or when it is acquired, its price is now higher because it includes this (now higher) "assembly fee." If this rise in price is financed partly through additional debt that the new entity inherits, firms' earnings (which include payments to debt-holders) will rise while firms' profits (which exclude them) will also rise but by less. The model thus connects the firm specificity of inputs to the share of output captured by management, and can therefore explain the simultaneous rise of the managerial premium and the rise in the earnings of firms.

In our paper, management performs a general function, that of firm assembly. Management capital has not become more firm specific, but the capital of the assembled assets has - so the argument runs. This difference is critical for comparing our model with that of Lustig, Syverson and Van Nieuwerburgh (2007, 'LSV'), and the evidence on managerial turnover is especially helpful for making the comparison. In LSV's model, a rising $\mathrm{q}$ is driven by forces that raise the attachment of managers to firms. LSV argue that the organizational capital of firms depreciates more slowly now than thirty years ago so that the longevity of establishments and the tenure of their managers rises, i.e., their turnover falls.

The plan of the paper.- Section 2 documents the three facts listed above. Section 3 gives a simple example around which the model revolves. Section 4 presents the model itself. Section 5 simulates the model and compares it to data. Section 6 discusses the nature of the information capital that our paper focuses on, and we draw our conclusions together in Section 7.

\section{The main facts}

This section documents the three claims listed in the introduction. Here we are stressing trends, not waves. We divide the evidence into categories, based on whether it motivates the assumptions, or whether it is explained by the model. The first and second subsections deal with evidence that the model explains, while the third

and fourth deal with evidence that motivates the assumption of a rising specificity of capital. 


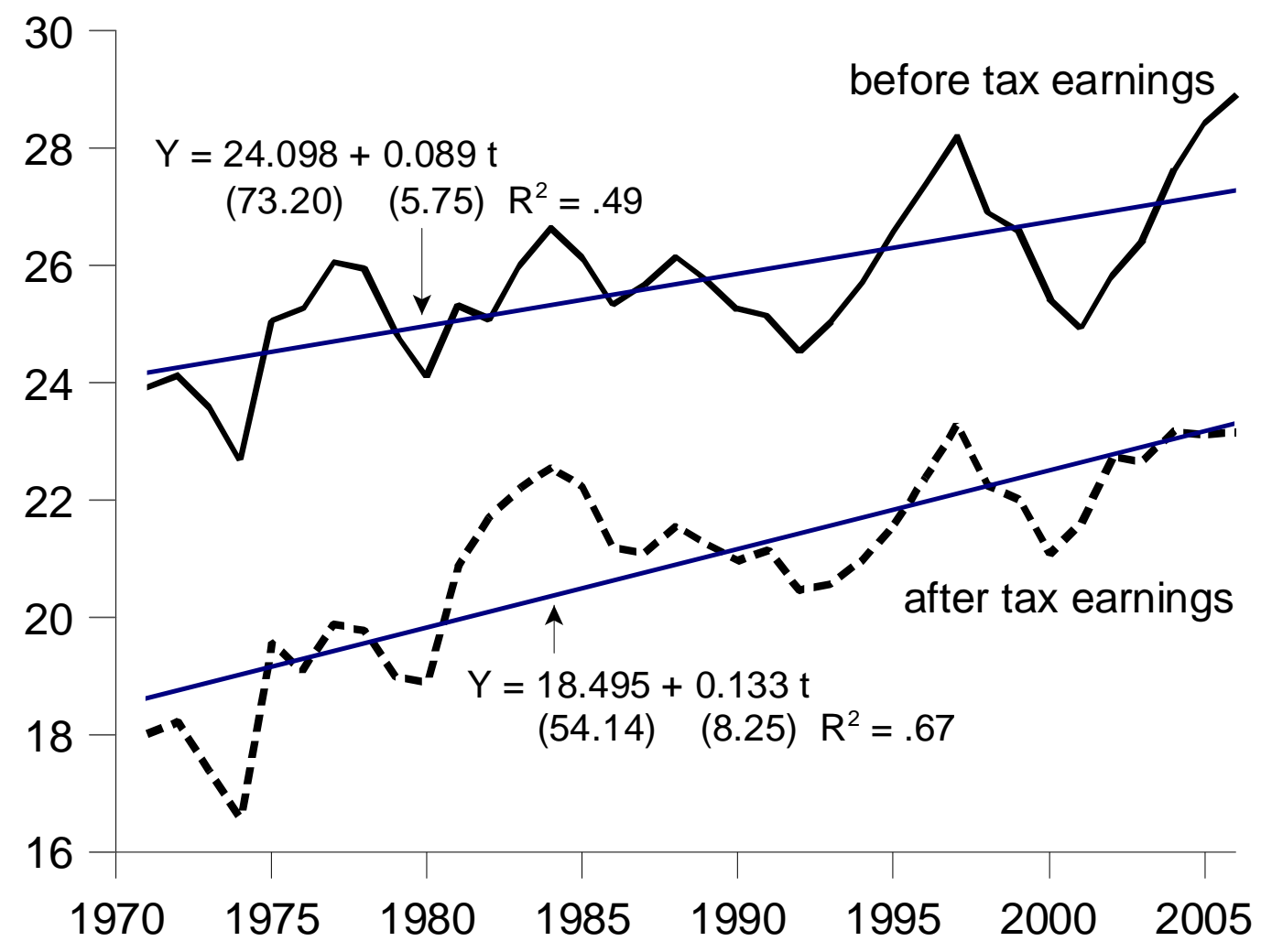

Figure 1: Corporate Earnings as Percentages of gross Value AdDed, 1971-2006.

\subsection{Earnings}

The top series in Figure 1 and its accompanying regression line (with t-statistics in parentheses) show an upward trend in corporate earnings as a percentage of value added in the corporate sector from 1971 to 2006. This trend is not due to changes in the tax code, as shown by the lower series in the figure, which removes taxes paid on corporate income, production, and income. Indeed, the trend lines indicate that after-tax earnings have grown more rapidly than before-tax earnings. ${ }^{4}$

Figure 2 shows the average rate of return on capital for seven major countries as compiled by the Organization for Economic Cooperation and Development (OECD). The overall average across the seven countries rises from 13.1 percent in 1977 to 16.2

\footnotetext{
${ }^{4}$ We compute the corporate earnings share using the National Income and Product Accounts (NIPA) published by the Bureau of Economic Analysis (2007) as the sum of profits before taxes on corporate income (table 1.14, line 11), net interest (table 1.14, line 9), and capital consumption (table 1.14, line 2) divided by gross value added (table 1.14, line 1). After-tax earnings are computed similarly, except that profits after taxes on corporate income (table 1.14, line 13) replace before-tax profits in the calculation.
} 


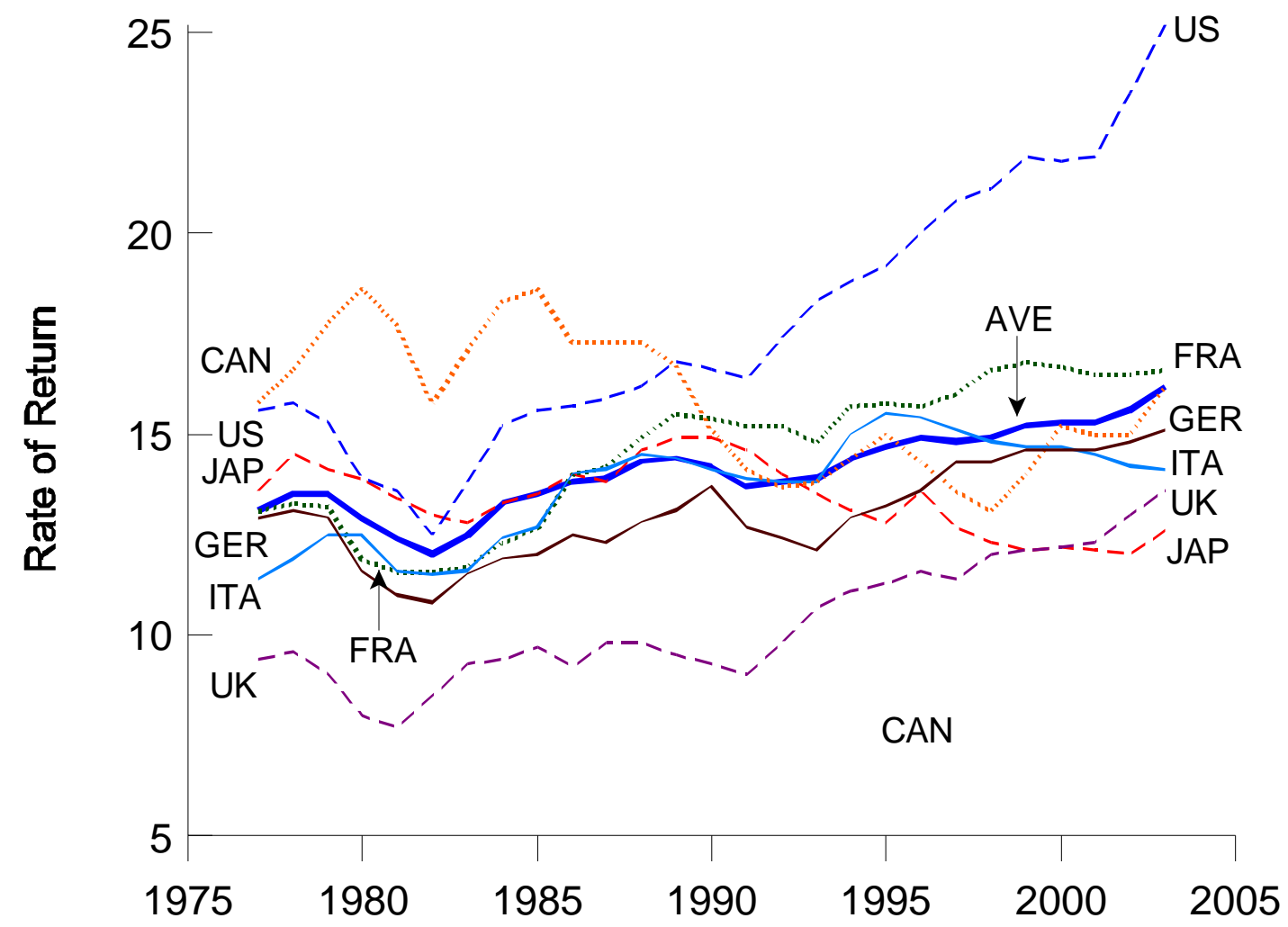

Figure 2: The RATE of Return on Business-SECTOR CAPITAL For SEVEn OECD COUNTRIES, 1977-2003.

percent by 2003, with only Canada and Japan not seeing increases over the period. ${ }^{5}$ And though the rate of return on business capital is not precisely the same object as plotted in Figure 1, this international evidence suggests that the upward trend in earnings is not just a characteristic of U.S. corporations.

\footnotetext{
${ }^{5}$ The returns to capital are from December issues of the OECD Economic Outlook $(1993,1997$, 1998; annex table 25) for 1977-1997. Blanchard (1996) uses these same data in an earlier investigation of profit rates and capital shares. The OECD constructs the rate of return as GDP in the business sector less total compensation of business employees and unpaid family workers, divided by the business sector's capital stock. The OECD suspended publication of the return to capital with the 1998 print version of the Economic Outlook, but continues to maintain the components needed to update the series. We did this, after consulting with the OECD on data and methods, for 1998-2003 and joined the results to the series in the earlier print versions.
} 


\subsection{The management premium and Tobin's $Q$}

The solid line in Figure 3 shows that Tobin's $Q$ 's among exchange-listed firms has risen from 1971-2005, as has the skill premium. ${ }^{6}$ The two series have a correlation coefficient of 0.68 in their overlapping years. Of course, the returns to schooling are a weak proxy for the management premium, and trends in manager's real compensation may be more telling. Direct evidence on the management premium provided in Figures 4 and 5 of Frydman and Saks (2007) show that managerial earnings are strongly correlated with the S\&P 500 index and, hence, with Tobin's $Q$.

McGrattan and Prescott (2001) have argued that taxes explain the rise in Tobin's $Q$ since, say, 1960. We doubt that taxes play a large role because Tobin's Q was about as high in the early 1900s as it was in the early 1970s (Wright 2004, Figure 5), and yet taxes were at their lowest early in the 20th century - certainly lower than today. Figure 3 suggests there may be a single explanation for the rise in $\mathrm{Q}$ and in the skill premium.

\subsection{Labor turnover}

While the previous two subsections describe facts that the model explains, the next two subsections document indirect evidence of increased specificity of human capital, namely evidence that labor turnover has declined, and evidence that occupation codes have proliferated Although our model does not generate labor turnover, it is commonly agreed that specific capital is a major deterrent to labor turnover. And while we do not explicitly consider product variety, the presumption is that increased industry specificity and increased occupational specificity must reduce the number of firms that can use a given worker's services.

Labor turnover fell dramatically during the 20th century. Figure 4, which shows annual job separation rates from 1971 to 2006 using various sources demonstrates this fact for the United States. ${ }^{7}$ Mincer and Higuchi (1988) offer evidence that labor

\footnotetext{
${ }^{6}$ For Tobin's Q, we use fourth quarter observations underlying Hall (2001, p. 1197) for 19781999, and join them with estimates compiled by Andrew Abel to bring the series forward to 2006. Hall computed $\mathrm{Q}$ as the ratio of the value of ownership claims on the firm less the book value of inventories to the reproduction cost of plant and equipment, with the latter inferred via a standard perpetual inventory of observed physical investment and a depreciation rate of 10 percent per year. Abel calculates Q as the ratio of net ownership claims to physical assets as reported in the Flow of Funds data. The "skill premium" series shows the relative returns to 16 versus 12 years of schooling for men from 1971 to 1995 from Goldin and Katz (1999). Since the Goldin and Katz observations are generally decadal, we interpolate between them to obtain an annual series for 1971 to 1995 .

${ }^{7}$ The turnover data given by the solid line are for the manufacturing sector and include job separations due to quits, layoffs, and discharges. They are from the Monthly Labor Review of the Bureau of Labor Statistics (BLS) for 1971-80. We then linearly interpolate between the observation for 1980 and the next available BLS estimate in 2000, which marks the start of a new initiative at the BLS to collect job turnover data. The dotted line from 1971-1980 shows job separations in which a worker changed sectors from Jovanovic and Moffitt (1990, table 4, p. 844), and is continued
} 


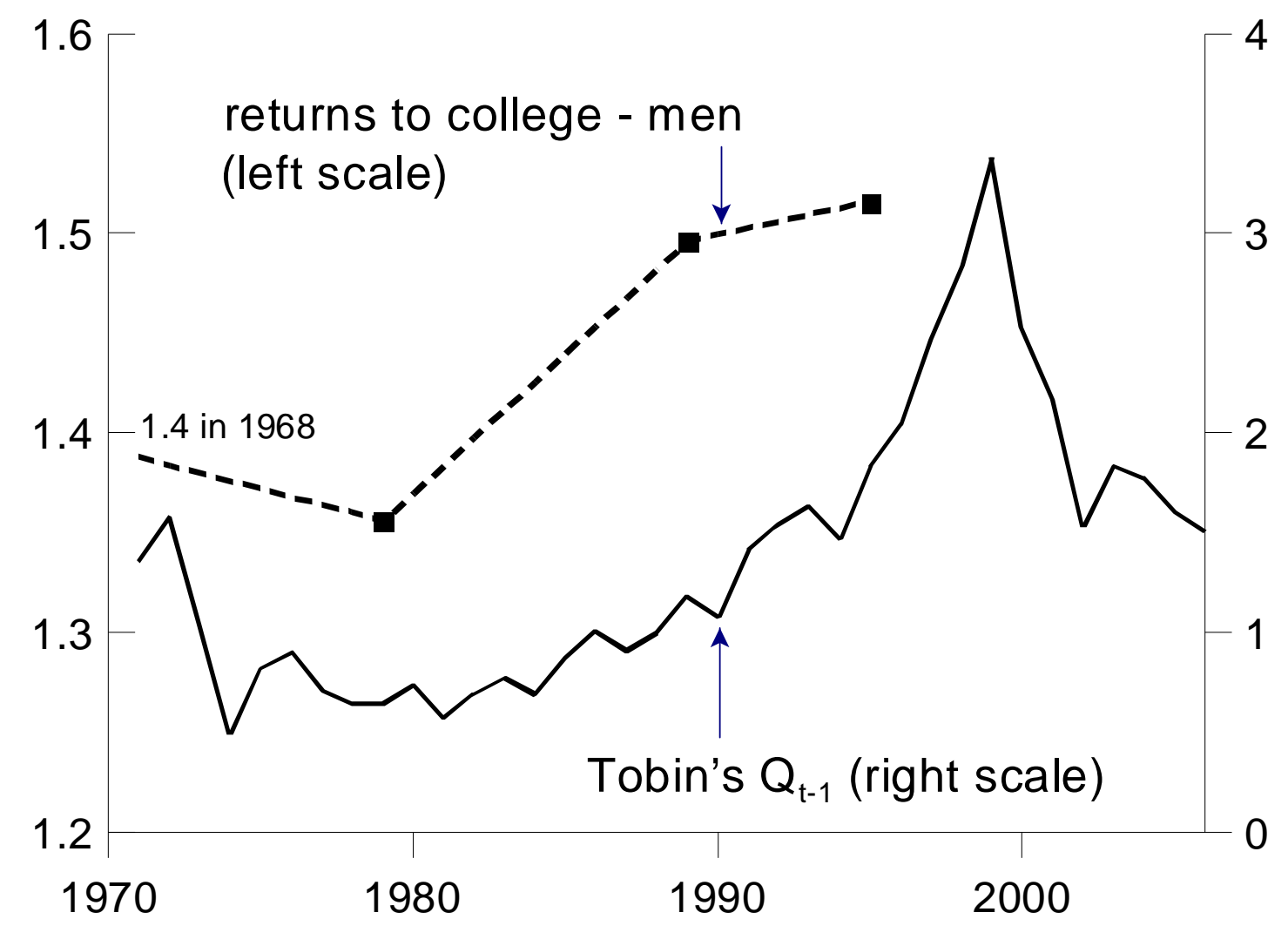

Figure 3: The Skill Premium and Tobin's Q, 1971-2006.

turnover fell in Japan over the 1971-1985 period as well. We interpret this rising attachment of workers to firms as the result of a rising specificity of their human capital which, itself, derives from the increase in technological variety. Equations (13)-(15) of Dagsvik, Jovanovic and Shepard (1985) show how the variance of match quality between a firm and a worker rises with the heterogeneity of the technologies that firms use. The model we shall present generates no turnover, but if firm-specific skills have indeed become more important, then it will take a larger sectoral shock for a worker to be displaced.

In interpreting the pattern in Figure 4 as evidence for rising specificity, we have implicitly assumed the following background model of labor turnover: The quality of the match between the asset and the firm is what Lippman and McCall (1981) call

using separation rates for all sectors based on March issues of the Current Population Survey (CPS) from Stewart (2002, table 1). Moscarini and Vella (2003), also using the CPS, find that mobility across 3-digit sectors declined from 1971-2000. Kambourov and Manovskii (2008), however, using a smaller sample from the Panel Study of Income Dynamics that excludes public employees, report a modest increase in occupational mobility over the same period. 


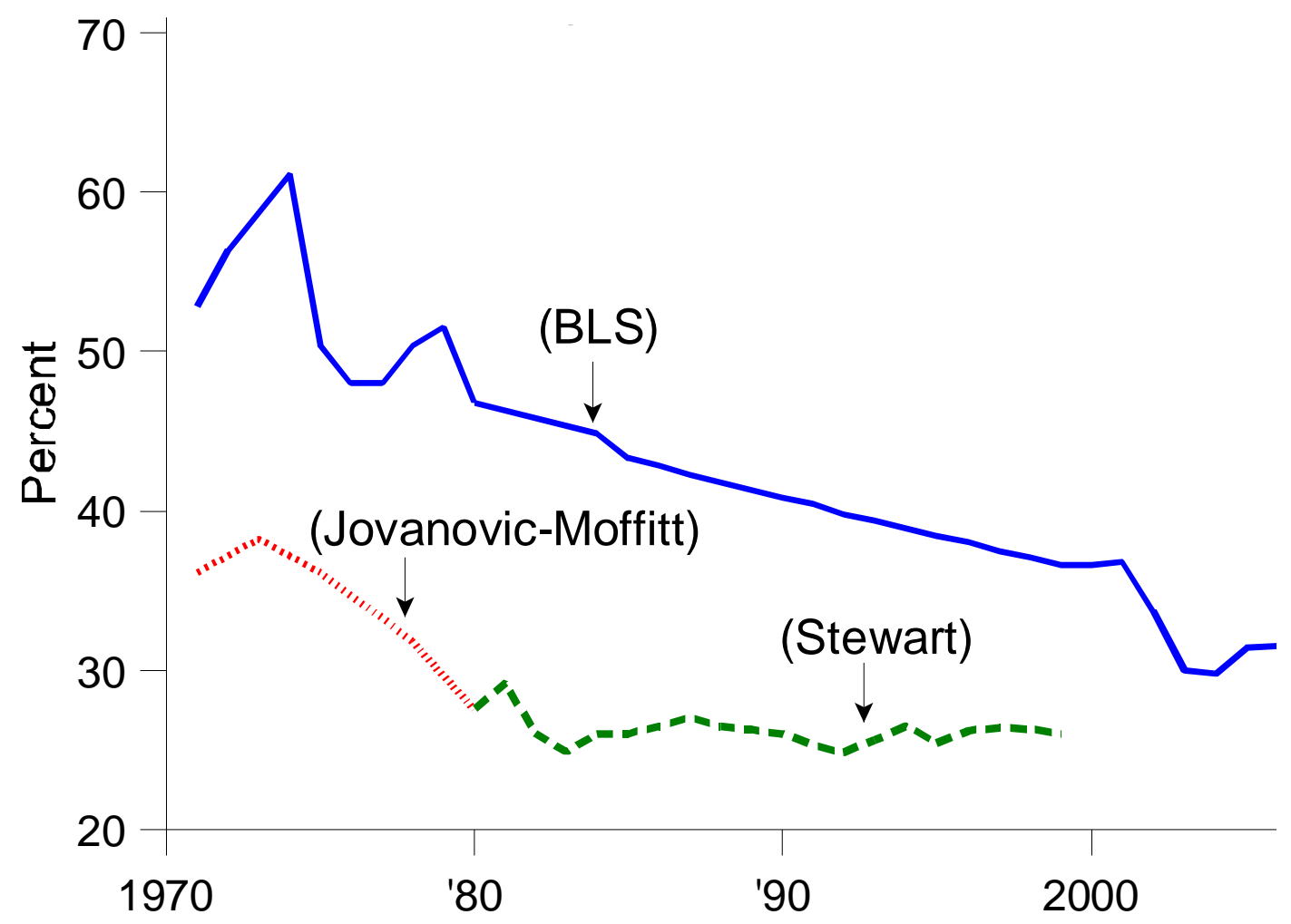

Figure 4: AnNual Labor turnover Rates, 1971-2006.

an 'inspection good.' By this they meant that the quality of the match is discovered before the match forms, and no subsequent deterioration or improvement of that quality occurs thereafter. ${ }^{8}$ In the face of other shocks, then, a dispersed distribution of the quality of the match over possible assignments means that those matches that do form are further in the right tail and that such matches will survive a greater range of outside shocks - shocks to demand and to the prices of other inputs for example. Thus as the dispersion of match qualities rises over time while the amplitude of the other shocks remains roughly constant, labor turnover ought to fall.

The rising specialization of the labor force is also reflected in an upward trend in the number of occupations in the occupational classification system. The number of occupations stood at 441 in 1970, at 503 in 1990, and 509 in 2000 (U.S. Census Bureau 2003, pp. 4-5). Indeed, if both human and physical capital have become

\footnotetext{
${ }^{8}$ Jovanovic and Moffit (1990) assume, in contrast, that the quality of the match is an 'experience good' in the sense that its quality is revealed only after the match is experienced for a period. In such a model, a secular rise in the dispersion of match quality would have the effect opposite to that which we are assuming here, namely, a secular rise in the dispersion of match quality would cause labor turnover to rise.
} 


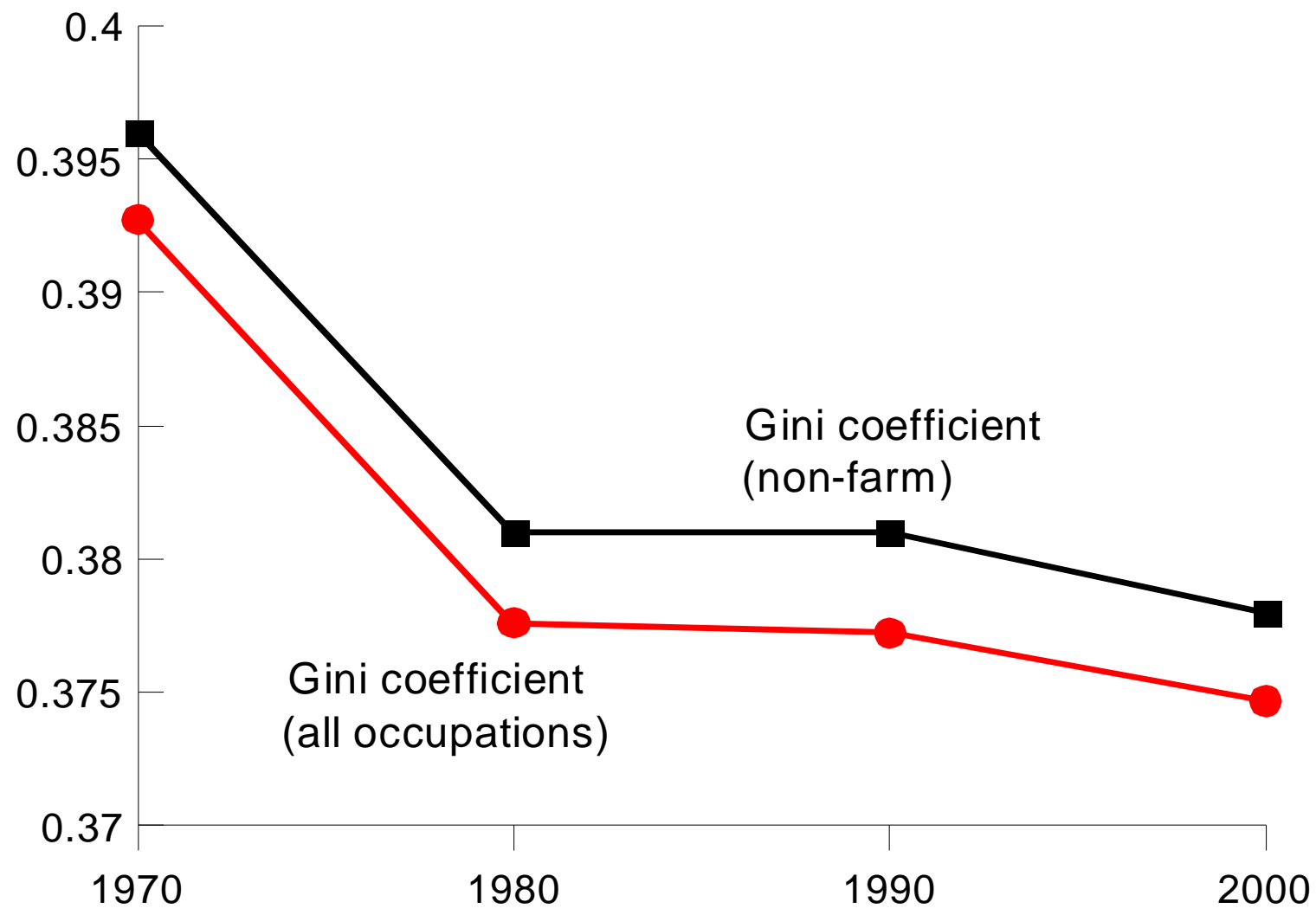

Figure 5: Gini coefficients for counts By occupation Code, 1970-2000.

more firm specific, we might also find that the workforce has become more uniformly distributed across occupations. The Gini coefficients shown in Figure 5 for occupation counts from the Integrated Public Use Microdata Set (IPUMS) based on decadal U.S. censuses from 1970 to 2000 suggest that this could well have been the case.

Importantly, labor turnover has declined while the turnover of managers has risen, as Kaplan and Minton (2006), and Lucier et. al (2007) document. Between 1995 and 2006, annual CEO turnover has grown from $11 \%$ to $15 \%$ in North America, from $3 \%$ to $15 \%$ in Europe, stayed flat at $15 \%$ in Japan and grown from $5 \%$ to $10 \%$ in the rest of Asia/Pacific (Lucier, Wheeler and Habbel 2007, Figure 2, their Figure 1 shows that acquisitions were not the main driver of this rise). Kaplan and Minton (2006) report similar, but slightly less dramatic numbers for the U.S. Fortune 500 companies over the period 1992-2005. All this suggests that inputs have become specific relative to the managerial inputs that are combined with them. 


\subsection{Management and the 'assembly' of the firm}

The last century has seen a rise in the role of the manager (Nelson 1995), and the last 30 years have produced a rise in venture capitalism. The venture capitalist, especially, focuses on the formative stage of a business. The term "assembly" is supposed to represent the stage at which the firm has negative cash flows, a stage that every firm goes through at the outset. The rising importance of the process of assembly itself originates in our demand for a more rapid succession of new products.

A venture capitalist, together with the founder of a firm, assembles assets around an idea. The idea belongs to the firm, and the people and assets should be suited to the implementation of that idea. If the right team and right assets are assembled, the ratio of market to book value of the firm at IPO will be high.

An existing firm also must periodically move to new activities and new products. Banking, for example, is one place we see clear examples of how firm-specific capital, both physical and human, are assembled. Before buying a building, a retail bank wants to know if the likely customers will value its products. Management studies the demographics to see if the building is a good match for the bank's needs.

An investment bank will sometimes bid for an entire team of analysts from another bank. Before doing so, its management evaluates whether that team's human capital is a good match for the bank's own needs. For example, management will want to know if the team has expertise in those areas where its own sales force specializes.

If the market for used capital was liquid, evaluative expertise would not matter buying the wrong building or hiring the wrong people could be reversed without cost. But informational and other frictions make it costly to trade used equipment and to move people around. Our model will assume that the only role of the manager is that of assembling the firm's assets. Our model emphasizes the rise in the manager's value added. In that sense it is consistent with Gabaix and Landier (2008) who also argue that the value added by at least the top managers has risen because the stock-market value of the firms they manage has risen over the past 30 years.

\section{Example}

The following example of a single auction shows how specificity translates into a division of rents. The model in Section 4 will place this into an equilibrium setting, and Section 5 will present simulations of the model.

Consider a second-price auction for one asset, "capital," with two firms bidding for it. Each bidder independently draws a value of the object, $z$, from the following distribution:

$$
z=\left\{\begin{array}{ccc}
1 & \text { with prob. } & \frac{1}{2} \\
z_{0} & \text { with prob. } & \frac{1}{2}
\end{array}\right.
$$


The winner of the auction pays what the loser has bid, and so it is optimal to bid one's own value. Therefore we have the following three types of outcomes:

1. Both bidders draw $z=1$. All rents go to capital; the bidders get nothing,

2. Both firms draw $z=z_{0}$. Again, all rents go to capital, and

3. One firm draws $z=1$, the other draws $z=z_{0}$. Capital gets $z_{0}$, and the winning bidder gets $1-z_{0}$.

Weighing the outcomes by their probabilities, the expected values are as follows:

$\begin{array}{lc}\text { Output } & \frac{\left(3+z_{0}\right)}{4} \\ \text { Share of capital } & \frac{1+3 z_{0}}{3+z_{0}} \\ \text { Share of firm } & \frac{2\left(1-z_{0}\right)}{3+z_{0}} .\end{array}$

We plot these three quantities as a function of $z_{0}$ in Figure 6.

Specificity of capital. - The specificity of capital can be measured as $1-z_{0}$. As $z_{0}$ falls and capital gets more specific, output falls, but the share of the firm rises more than enough to offset this decline. Thus output falls but the value of firms rises. This explains why the value of businesses as measured by $Q$ can rise in the midst of a productivity slowdown.

In our model, the capital of managers is completely general - their function is solely to evaluate the factors and they can perfectly evaluate any item that they bid for. It is the quality of the match between the factors themselves and the firm that widens. That is, it is the capital of the workers and machines that becomes more specific. Contrast this explanation to that of LSV. In their model it is the workers that are homogeneous and the managers that have match-specific quality. In modeling the IT period (which they date the same way that we do), they assume that the fraction of managerial human capital that is general to all firms rises. The specific component is tied to a firm and to a particular technological vintage. They assume that IT raises disembodied progress relative to the embodied part, thereby raising the portion of managerial human capital that is general to all firms. Thus the building blocks of the two models are different. In section 2.3 we documented the rise in managerial turnover and the fall in worker turnover.

\section{Model}

A firm's production function.-The firm's inputs are management and "broad capital" $k$. Its output, $y$, is

$$
y=\sum_{i=1}^{k} z_{i}
$$


Output, and shares

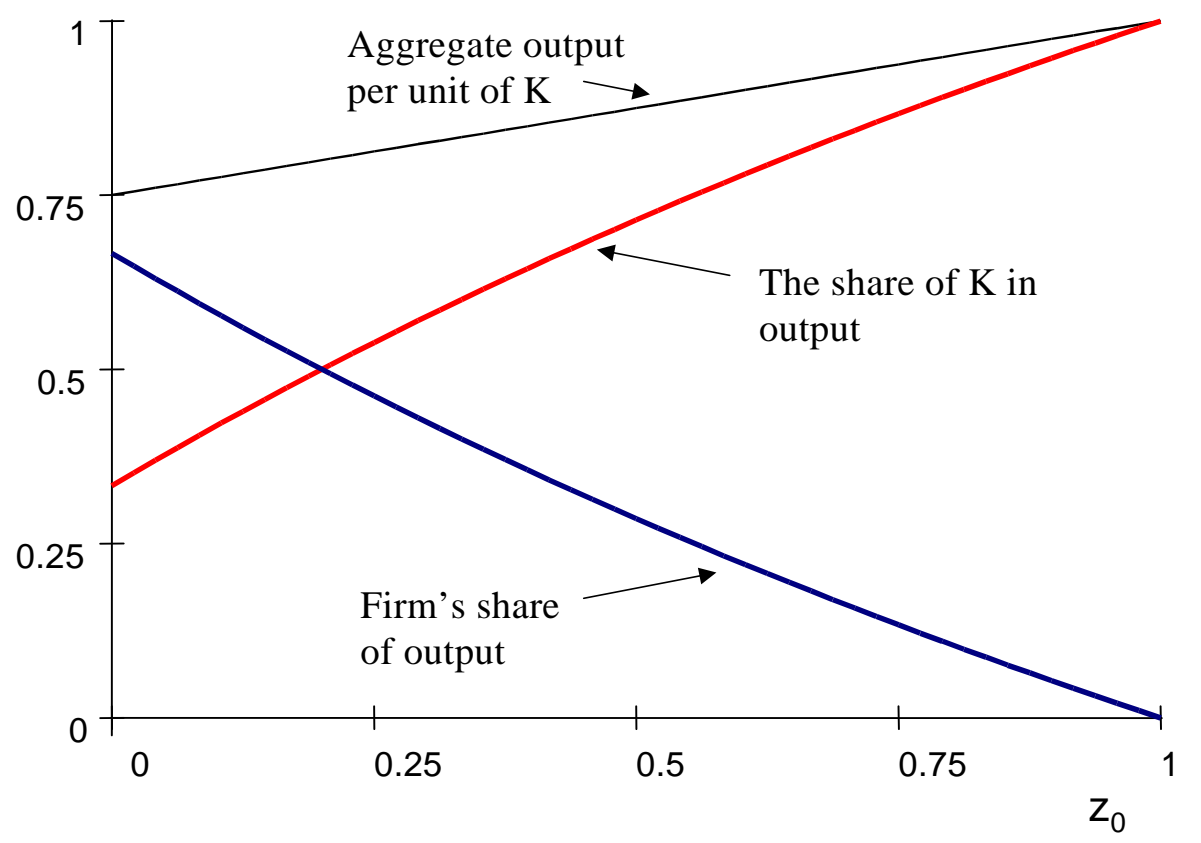

Figure 6: The EXPeCted Shares of The BIDDERS AND The ASSET.

where the $z_{i}$ are the qualities of each of the $k$ units of capital that a firm's manager has assembled. The managers task is to buy the best inputs as cheaply as possible. Capital is heterogeneous. The quality of the $i$ 'th unit of capital, $z_{i}$, is purely firmspecific, so that capital has no hierarchical quality dimension. Moreover, a manager can see $z_{i}$ before he bids for the $i$ 'th unit of capital.

Second-price auctions. - Each unit of $k$ sells in its own second-price auction unrelated to any other auction. ${ }^{9}$ Consider such an auction in which there are $m$ firms bidding. Suppose there are $K$ units of capital in the economy, and there are $M$ managers who also own their firms or operate them in the interest of their shareholders. Assume that every manager takes part in the same number of auctions, $\lambda$. Then the total number of bidders in the economy is $\lambda M$. Therefore, each unit of capital will have $m$ firms bidding for it, where

$$
m=\lambda \frac{M}{K} .
$$

A manager maximizes the expected dividends and, hence, the value of the firm to the risk-neutral shareholders. So, $m$ managers bid for a single unit of capital in

\footnotetext{
${ }^{9}$ Under certain conditions, a whole range of auctions (including the second-price auction) yield the same, maximal expected revenue to the auctioneer (Myerson 1981). The second-price auction is the simplest to analyze.
} 
a second-price, sealed-bid auction (i.e., the object goes to the highest bidder who pays the second-highest bid). Although they target other issues, Julien, Kennes and King (2000) relate closely to our model because they too model the labor market as a collection of auctions in which multiple firms bid for the services of individual workers.

Idiosyncratic match quality. - Capital and firms are ex ante the same, but the quality of the match between assets and managers is random and unknown. Let $F(z)$ be the distribution of $z$. Firms value a given unit of capital differently, and this is what we mean by the "firm specificity" of capital. A manager learns the match quality $z$ only after he commits to attending the auction for the asset in question. Although a worker's productivity in various firms can differ for many reasons, the main reason, as we see it, is that firms use different technologies and produce different goods.

\subsection{Analysis of a single auction}

Let the subscript $j \in\{1, \ldots, m\}$ index the bidders in the auction for this object. A manager has a private signal about the productivity (in his firm only) of the capital good. Each manager has a perfect private ex-ante signal about his ex-post private value $z_{i}$ of owning the object. In a second-price auction the firm's own bid affects only the probability that it wins the object, but not what it actually pays. Moreover, the $z_{i}$ do not have an unknown common component. Hence, the dominant strategy for a manager is to bid

$$
b_{i} \equiv z_{i}
$$

A firm that wins the auction pays the price $q_{i}=\max _{j \neq i} z_{j}$. The winning firm's profit and dividend is

$$
\delta_{i}=z_{i}-q_{i}
$$

Determining the division of the rents.-Let

$$
F(z)=\text { C.D.F. of } z \text { in the population of all matches. }
$$

The distribution of the winning firm's $z$ is $F^{m}(z)$. Therefore the expected output of the winning firm's unit of capital is

$$
y=\int_{0}^{\infty} z d F^{m}(z) .
$$

Conditional on a particular winning $z$, the C.D.F. of the price paid, $q_{i}$, is

$$
\left(\frac{F(q)}{F(z)}\right)^{m-1} \text { for } q \in[0, z] \text {, }
$$


so that the expected price paid conditional on $z$ is

$$
E(q \mid z, m)=\frac{1}{F^{m-1}(z)} \int_{0}^{z} q d F^{m-1}(q) .
$$

Therefore, the expected payment to the capital purchased in the average auction is

$$
\alpha=\int_{0}^{\infty} E(q \mid z, m) d F^{m}(z)
$$

and the ex-ante expected profit on the deal, $\delta$, going to the winning bidder is

$$
\delta=y-\alpha
$$

The effect of a rise in $m$.-We shall endogenize $m$ presently. But first let us see how changes in this variable affect the rents when the parameters are held fixed. A rise in $m$ unambiguously raises $q$, but it also raises the maximum $z$, and so the effect on $\delta$ is ambiguous. In general, how the change in $m$ will influence the distribution of the difference between the two highest observations depends on the hazard rate of $F$. If $z$ is bounded, however, then a sufficiently high $m$ shrinks $\delta$ to zero.

Example.-Suppose $F$ is the uniform distribution on $[0,1]$. In the case where $z$ is uniformly distributed,

$$
E(q \mid z, m)=\frac{z(m-1)}{m} \quad \text { and } \quad E(z)=\frac{m}{m+1},
$$

so that

$$
\alpha=\frac{m-1}{m+1} \quad \text { and } \quad \delta=\frac{1}{m+1} .
$$

In this case, then, the decrease in $\delta$ and the increase in $\alpha$ are both monotonic in $m$.

Aggregation over auctions.-Summing (1) over all $K$ auctions, aggregate output is

$$
Y=\bar{z}_{K} K, \quad \text { where } \quad \bar{z}_{K}=\frac{1}{K} \sum_{i=1}^{K} z_{i} .
$$

Dividing both sides by $K$ and letting $K$ become large, the law of large numbers implies the following:

- Productivity. - Output per unit of $k, \frac{Y}{K}$, converges to $y$ in (3),

- Share of managers.-This share converges to $\delta / y$, where $\delta$ is given by (5),

- Share of other factors. - The share of $K$ in output converges to $\alpha / y$, where $\alpha$ is given by (4), and 
- Tobin's $Q$.- If a firm had just a single asset, its $Q$ would simply be the expected value of the firm's dividends divided by the purchase price of its capital: $\frac{z}{p_{k}}$. Aggregate $Q$ does not depend on how assets are distributed over firms, but is just the ratio of the value of aggregate output divided by the total input cost, i.e.,

$$
Q=\frac{\alpha+\delta}{\alpha} .
$$

This corresponds to the construction of the variable plotted in Figure 3, calculated as the sum of share values divided by the sum of book values.

\subsection{Endogenizing $M$ and $K$}

There are two periods, ' 0 ' and ' 1 ' and there is no aggregate risk. Agents are born alike, with a utility function

$$
U\left(C_{0}\right)+\beta U\left(C_{1}\right),
$$

where $C_{0}$ and $C_{1}$ are the first and second period consumptions. Each agent has a first-period endowment $\omega$ of the consumption good that he can consume or convert one-for-one into $K$, or convert into $M$ at a cost of $\phi$. A safe asset exists and the rate of interest is $r$.

Auctioneers.-Any agent can host an auction for someone else's unit of $K$. Auction outcomes are costlessly and fairly insurable. Competitive auction dealers in $K$ (i.e., intermediaries in $K$ ) will then pay

$$
p_{K}=\frac{\alpha}{1+r}
$$

for a unit of $K$ today and earn an expected sale of $\alpha$ in the second period for each unit of $K$ that they now buy. Agents hold a representative portfolio of these auction dealers, and the portfolio yields a safe return $r$.

Firm formation and "IPO".- - As in Diamond (1982), a person cannot use his own $K$ in his production function - he must go to an auction and buy $K$ there in the way that we have described in Section 4.1. Each unit of $M$ takes part in $\lambda$ auctions. The probability of winning any single auction is $1 / m$ and so a unit of $M$ expects to win $\lambda / m$ auctions altogether. The agent compiles $M$ units of management capital in period 0 and at once floats his firm in an IPO in period 0 . The firm's price at IPO is just the period-0 expectation of the value of the claims to the dividend that the firm (which the agent assembled) will pay in period 1. A unit of $M$ delivers participation in $\lambda$ auctions and $\delta$ in proceeds from every auction won. The probability of winning an auction is the same for all of the $m$ bidders in that auction, and therefore

$$
p_{M}=\frac{1}{1+r} \frac{\lambda \delta}{m},
$$


where $p_{M}$ is also the price per unit of $M$. The portfolio of all IPOs also yields a safe return of $r$. Thus both assets will be subsumed in the consumer's budget constraint by a discounting of future consumption purchases at the rate $r$.

Consumer lifetime budget constraint. - The numeraire in the lifetime budget constraint is current consumption. The agent's resources are his endowment, $\omega$, and the proceeds from his two types of entrepreneurial activity, i.e., $p_{K} K+p_{M} M$. The constraint is thus

$$
C_{0}+\frac{1}{1+r} C_{1}+K+\phi M=\omega+p_{K} K+p_{M} M .
$$

The right-hand side of (10) are resources, and the left-hand side are expenditures. The equilibrium ratio $p_{M} / p_{K}$ is the 'management premium.'

Assets.-There are two assets: Claims to the revenues of auction houses, and claims to the dividends of assembled firms. The portfolio of all auction houses is a safe asset, as is a claim to the revenues of assembled firms.

First-order conditions.-After eliminating the Lagrange multiplier on (10), the FOC with respect to $K$ is,

$$
\frac{1}{1+r} \alpha=1
$$

with respect to $M$ it is

$$
\frac{1}{1+r} \frac{\lambda \delta}{m}=\phi
$$

and with respect to $c_{0}$ and $c_{1}$ it is

$$
\frac{1}{1+r}=\beta \frac{U^{\prime}\left(C_{1}\right)}{U^{\prime}\left(C_{0}\right)} .
$$

Demand $=$ Supply. - All agents consume the same, $c_{0}$ and $c_{1}$ which, therefore, also denote aggregate consumption in the two periods. In the second period the goods market clears and all output is consumed:

$$
C_{1}=y K
$$

The lifetime budget constraint (10) must hold when aggregate values of the variables are substituted into it. Finally the asset market must be in equilibrium when the values of aggregate consumption are substituted into the first-order condition (13) for $C_{0}$ and $C_{1}$. A further condition is the bidding proportions equation (2).

An upward-sloping supply curve of $M$.- To keep the model simple, we retain the representative agent and assume an aggregate congestion cost in the creation of $M$. That is,

$$
\phi=\phi(m)
$$


where $m$ satisfies (2) evaluated at the economy-wide ratio $M / K$ that each agent takes as given. We assume that $\phi^{\prime}>0$, which is a type of congestion externality (pecuniary or non-pecuniary) in creating $M$, perhaps because it requires the presence of an unmodeled scarce input. ${ }^{10}$

Equilibrium.-The endogenous variables are $m, r, \alpha, \delta, y, c_{0}, c_{1}, K$, and $M$, and they must solve (2), (3), (4), (5), (8), (9), (10), (11), (12), (13), and (14). Some of these equations are redundant - being implied by the other equations - but they all must hold.

Solving for $m$.- We now show that the model reduces to a simple equation in $m$ alone:

$$
\phi(m)=\frac{\lambda}{m} \frac{\delta(m)}{\alpha(m)},
$$

where $\alpha$ is defined in (4) and $\delta$ in (5). To show (15), note first that from (8) and (9),

$$
\frac{p_{M}}{p_{K}}=\frac{\lambda \delta}{m \alpha}
$$

But using (11) and (12),

$$
\frac{p_{M}}{p_{K}}=\phi(m)
$$

Thus $\phi(m)$ is also the management premium.

$Q$ and the management premium.-A simple relation holds between the two: combining (7) and (15), we get

$$
Q=1+\left(\frac{m}{\lambda}\right) \phi(m)
$$

We thus find that a rise in $m$ raises $Q$ and the management premium.

Manipulation of (18) leads to the following useful relation between the growth rate of $Q$ and the growth rate of the skill premium: ${ }^{11}$

$$
\frac{d Q}{Q}=\left(1-\frac{1}{Q}\right)\left(1+\frac{1}{\varepsilon_{\phi, m}}\right) \frac{d \phi}{\phi},
$$

\footnotetext{
${ }^{10}$ Another way to have the same effect would have been to endow each agent with a different $\phi$. The low- $\phi$ agents would then be the ones opting for management, the high- $\phi$ agents would opt for creating $K$. This would lead to a nondegenerate distribution of managerial incomes and to more complicated algebra but the economics would stay roughly the same. The two formulations have roughly similar positive implications but radically different normative ones. The simpler, congestion route leads to the conclusion that competition creates too much $M$ relative to the planner's optimum but, as we just noted, it is hard to distinguish this empirically from the case where the equibrium is optimal and therefore we shall make no normative inferences whatsoever.

${ }^{11}$ Taking total derivatives in (18), $d Q=\frac{m}{\lambda} d \phi+\frac{\phi}{\lambda} d m=\frac{Q-1}{\phi} d \phi+\frac{Q-1}{m} d m$, and therefore

$$
\frac{d Q}{Q}=\left(1-\frac{1}{Q}\right)\left(\frac{d \phi}{\phi}+\frac{d m}{m}\right)
$$

i.e., (19).
} 
where, by (15),

$$
\varepsilon_{\phi, m}=\varepsilon_{\delta, m}-\varepsilon_{\alpha, m}-1,
$$

and where $\varepsilon_{i, j}$ denotes the elasticity of variable $i$ with respect to variable $j$.

\subsection{The effect of a rise in the specificity of capital}

The challenge in fitting both the growth in $Q$ and the rise in the skill premium is implicit in (19). Over our 1971-2006 sample, the growth of the skill premium (i.e., $\left.\frac{d \phi}{\phi}\right)$ averaged 0.003 and the sample average of $\left(1-\frac{1}{Q}\right)$ was only 0.08 . On the other hand $\frac{d Q}{Q}$ averaged at 0.03 . Then $\varepsilon_{\phi, m}$ would need to be around 0.008 , i.e., essentially zero.

The model has a hard time generating this quantitatively because for $\phi$ to be unresponsive to $m$ requires that $m$ be so large that virtually all the expected rents in an auction go to the asset and virtually none to the firm, i.e., when $m$ is already very high. But this would produce a level of $Q$ quite close to unity, and so we could fit the trend in $Q$ only by substantially underpredicting its sample average. The simulations will bear this out.

Now consider the experiment that we performed when analyzing the example in Section 3: Raise $\sigma_{z}$ by taking an inferior distribution of $z$ with a longer left tail. Such a rise in $\sigma_{z}$ raises $\delta(m)$ and lowers $\alpha(m)$. This also has the effect of raising $Q$ in $(7)$. Therefore the management premium rises, creating the incentive to create more $M$ and less $K$, so that $m$ will rise to offset this effect partially. But $\phi^{\prime}>0$ means that the rise in $m$ will not fully offset the initial stimulus, and therefore the effect will be a rise in both $Q$ and the management premium - see Figure 7. The figure plots both sides of (15).

When $\sigma_{z}$ rises from $\sigma_{1}$ to $\sigma_{2}$, the right-hand side of (15) - call it the demand curve - rises, whereas its left-hand side - call it the supply curve - remains unchanged. And $m$ must rise to restore equilibrium as illustrated in Figure 7 . The presumed rightward shift of the demand curve is hard to show in general, but will be true when, in the next section, we take a mean-preserving spread of a uniformly distributed $z$.

How can $Q$ rise permanently? The value of assembled firms reflects both $K$ and $M$, but only $K$ is on the books and only $K$ enters the replacement of a firm's assets as accountants have been calculating it. In the model, $M$ is homogeneous; what we believe really causes $\phi$ to rise with $m$ is the heterogeneity of managerial talent and a non-degeneracy in comparative advantage in supplying $M$. In such a world, the most talented managers would find it profitable to manage even when the unit return to $M$ is just slightly above that of the unit return to $K$. But as we move down the skill distribution or, rather, as we attract people whose comparative advantage in supplying $M$ is not that high, we must raise the price. Thus the supply of $M$ is positively sloped, even in the long run, or at least for as long as the distribution of managerial talents does not change. 


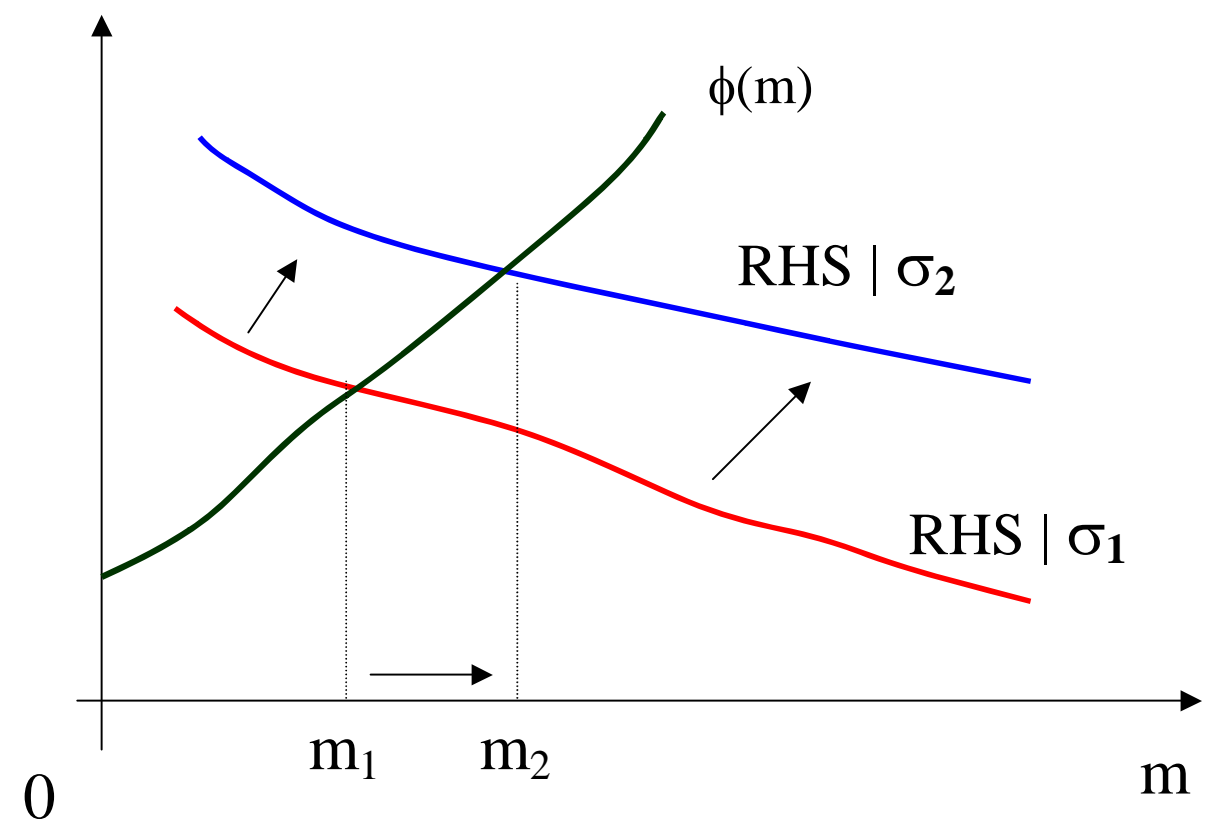

Figure 7: Comparative statics in (15): The effect on M OF A Rise in $\sigma_{z}$ FROM $\sigma_{1}$ TO $\sigma_{2}$.

\section{Simulations}

Assume now that $z$ is distributed uniformly on the interval $\left[1-\frac{\sigma}{2}, 1+\frac{\sigma}{2}\right]$, so that the mean of $z$ is unity and its range is $\sigma$. The parameter $\sigma$ indexes the specificity of capital, and we shall assume that it gradually rises over the post-1970 period. Applying the same logic as for equation (6),

$E(q \mid z, m)=1-\frac{\sigma}{2}+\frac{m-1}{m}\left(z-\left[1-\frac{\sigma}{2}\right]\right) \quad$ and $\quad E(z)=1-\frac{\sigma}{2}+\frac{m \sigma}{m+1}=y$,

so that

$$
\alpha=1-\frac{\sigma}{2}+\frac{m-1}{m+1} \sigma \text { and } \delta=\frac{\sigma}{m+1} .
$$

Substituting into (15) we have

$$
\begin{aligned}
\phi(m) & =\frac{\lambda}{m} \frac{\delta(m)}{\alpha(m)}=\frac{\lambda}{m} \frac{\sigma}{(m+1)\left(1-\frac{\sigma}{2}+\frac{m-1}{m+1} \sigma\right)} \\
& =\frac{\lambda}{m} \frac{1}{\left(\frac{1}{\sigma}-\frac{1}{2}\right)(m+1)+m-1} .
\end{aligned}
$$

When $\sigma$ rises, the RHS increases, as argued in Figure 7. Now let $A$ and $B$ be positive constants with

$$
\phi(m)=\frac{1}{A-B m},
$$


which increases to infinity as $m$ approaches $A / B$. That is, the positively sloping curve in Figure 7 becomes vertical at that point. The Appendix shows that the solution for $m$ is

$$
m=\frac{1}{2+\sigma}\left(-\left(1-\frac{3 \sigma}{2}+\sigma \lambda B\right)+\sqrt{\left(1-\frac{3 \sigma}{2}+\sigma \lambda B\right)^{2}+(4+2 \sigma) \sigma \lambda}\right)
$$

For the simulations we take the actual solution for $m$ in (21). The forcing variable will be $\sigma$ which we shall make a linear function of time:

$$
\sigma=\beta_{0}+\beta_{1} t
$$

These parameters $\left(\beta_{0}, \beta_{1}\right)$ will be chosen to minimize a squared deviation criterion between the model and the following variables:

Earnings - Expected output per unit of $K$ and economy-wide TFP is

$$
y=E(z)=1-\frac{\sigma}{2}+\frac{m \sigma}{m+1}
$$

and therefore earnings as a fraction of output are

$$
\pi \equiv \frac{\delta}{y}=\frac{\sigma}{(m+1)} \frac{1}{1-\frac{\sigma}{2}+\frac{m \sigma}{m+1}} \quad \text { (earnings) }
$$

The management premium.-Combining the above information with (16), the management premium is

$$
\frac{p_{M}}{p_{K}}=\frac{\lambda \delta}{m \alpha}=\frac{\lambda \sigma}{m+1} \frac{1}{m\left(1-\frac{\sigma}{2}+\frac{m-1}{m+1} \sigma\right)} \quad \text { (management premium). }
$$

Tobin's Q.- Using (7),

$$
Q=1+\left(\frac{\sigma}{m+1}\right) \frac{1}{1-\frac{\sigma}{2}+\frac{m-1}{m+1} \sigma} \quad(\text { Tobin's } Q) .
$$

Simulation results. - Figure 8 shows the model's fit for three series of interest: after-tax earnings (panel a), the management i.e., skill premium (panel b), and Tobin's Q (panel c), using values for the key model parameters (A, B, $\lambda$, and $\sigma$ ). The parameters were chosen to meet a weighted least squares fitting criterion across the three observables, with the weights given by the inverse of the variances of the underlying de-trended series. The observables are given by the dashed lines and the model's predictions by the solid lines. This criterion fits after-tax earnings and the skill premium $^{12}$ well, but does not capture the sharp rise in Tobin's $Q$. This is because $m$

\footnotetext{
${ }^{12}$ The model also captures pretty well the rise in the management premium as reported by Frydman and Saks (2007), Figure 5.
} 


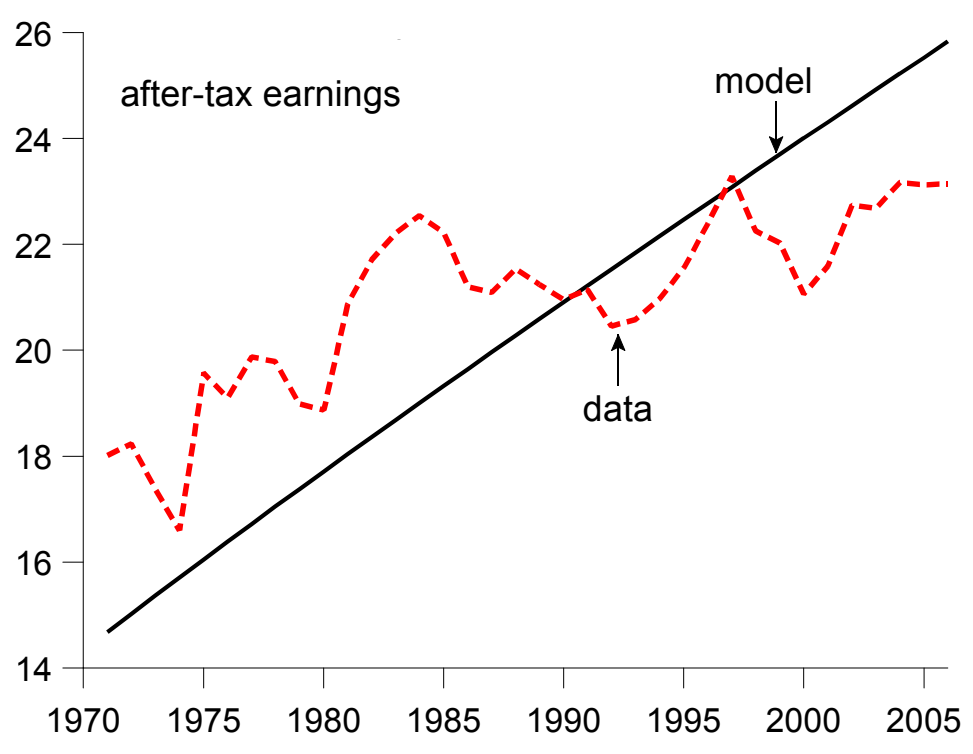

(a)

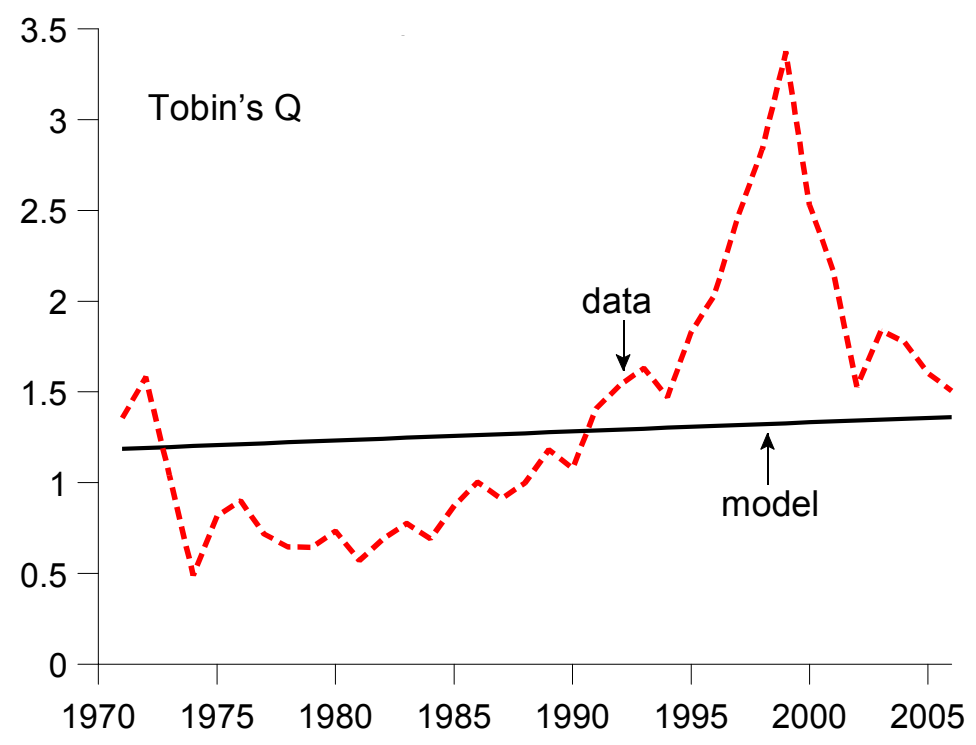

(c)

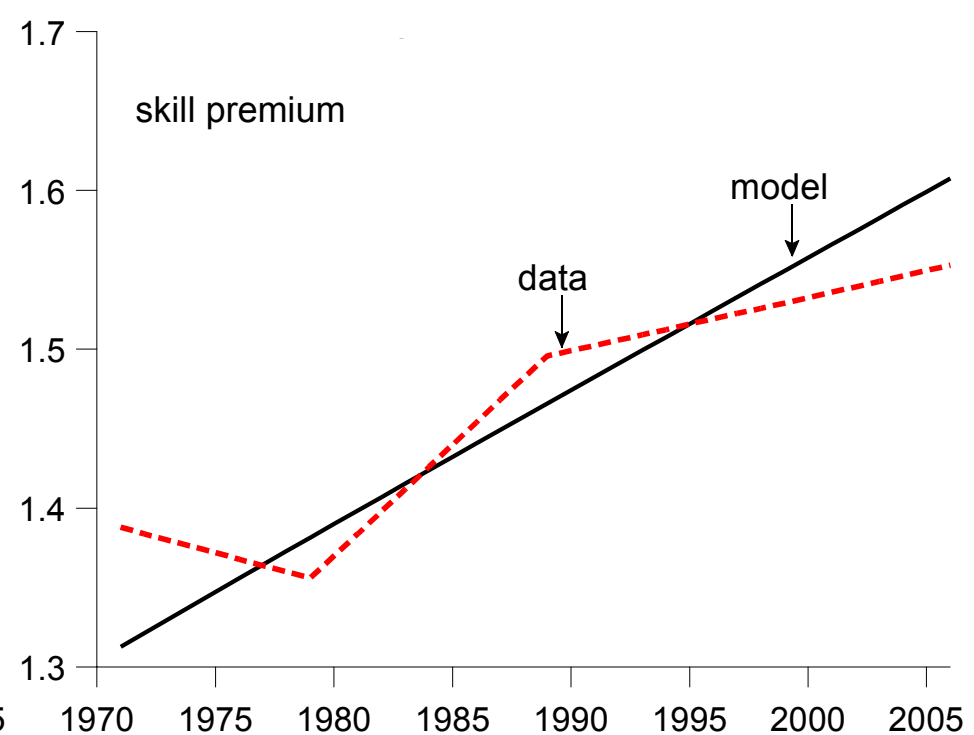

(b)

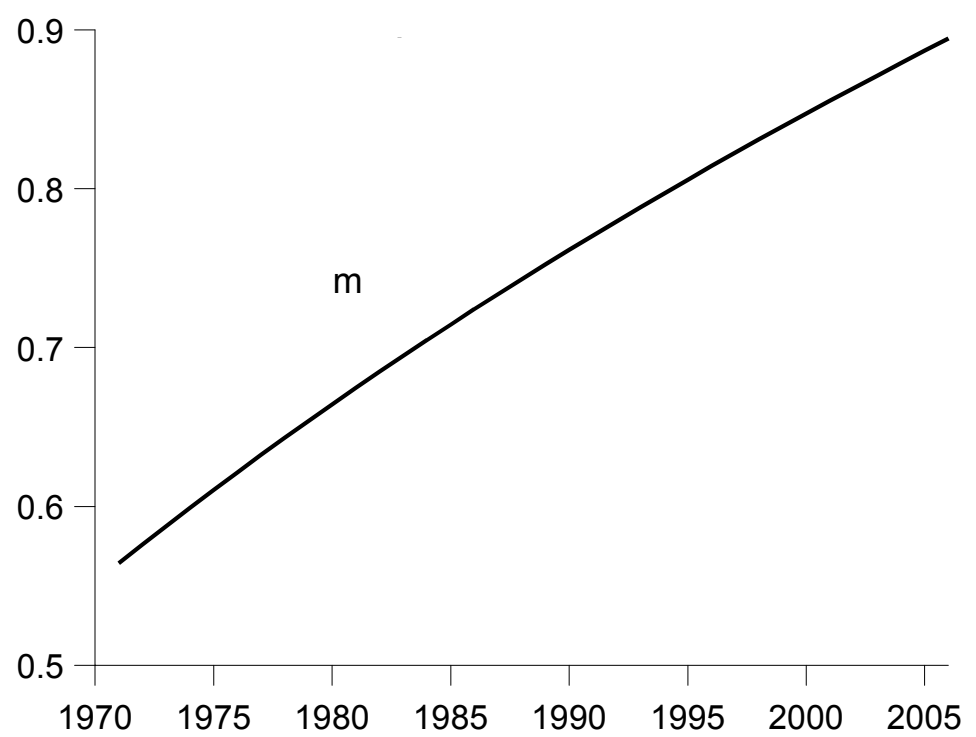

(d)

Model settings:

$\mathrm{A}=60.134, \mathrm{~B}=0.422, \lambda=3.977, \sigma=0.23+0.0074 \mathrm{t}$.

Figure 8: SIMULATED MODEL AND ACTUAL DATA. 
(panel $\mathrm{d})^{13}$ does not rise quickly enough under this parameterization to fit $Q$ while maintaining direct proportionality with the management premium, which does not vary as widely as $Q$.

Table 1 presents the intercept and slope coefficients for OLS regressions run through the estimated series and actual data displayed in panels (a), (b), and (c)

Table 1. Goodness of Fit in Simulations, 1971-2006

\begin{tabular}{|c|c|c|c|c|c|c|}
\hline & \multicolumn{6}{|c|}{ 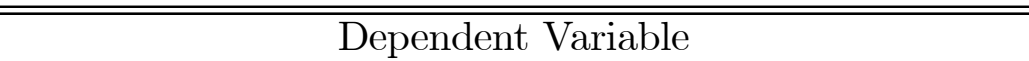 } \\
\hline & \multicolumn{2}{|c|}{ After-Tax Earnings } & \multicolumn{2}{|c|}{ Skill Premium } & \multicolumn{2}{|c|}{ Tobin's Q } \\
\hline & Model & Data & Model & Data & Model & Data \\
\hline constant & 14.497 & 18.495 & 1.306 & 1.344 & 1.182 & 0.538 \\
\hline time trend & 0.318 & 0.133 & 0.008 & 0.006 & 0.005 & 0.045 \\
\hline no. obs. & 36 & 36 & 36 & 36 & 36 & 36 \\
\hline
\end{tabular}

Note: All coefficient estimates are statistically significant at the 1 percent level.

of Figure 8. These coefficients indicate that the simulations overfit the actual data considerably for after-tax earnings, overfit the data slightly for the skill premium, and underfit Tobins's Q.

\section{The role of management and the concept of cap- ital used in our model}

We follow Prescott and Visscher (1980, 'PV') and model organization capital as information with an emphasis on the managerial function of assembling the most productive assets. Assembly takes place at auctions between randomly paired firms and workers. The matches that form at these auctions contain what one may call organization capital - capital formed by managers on behalf of firms for which they work. Firms pay managers to accumulate this capital.

There are two differences between PV's concept of organization capital and ours. First, in PV, a firm hires a worker and then screens that worker to determine which task (there are only two tasks and each firm requires both) matches the worker better. Second, and less essential, in PV matching occurs between workers and tasks, not workers and firms. In both models, then, organization capital consists of information about the quality of a match. The difference is that in PV it takes time for the parties

\footnotetext{
${ }^{13}$ This panel contains only the model's prediction for $m$; we have no direct empirical proxy for $m$.
} 
to the match to discover that quality whereas in our model the quality is known by inspection at the auction, before the bidding starts.

In our model, a mean-preserving spread of $z$ implies that there is no change in the quality of the average match, but that there is a rise in output of the economy when people are matched optimally as in the mechanism that our model assumes. We argued that this mean preserving spread is a natural consequence of a rise in specialization, but a critical component in the rise of productivity on the matches that form is the process by which assets are allocated to the firm, i.e., the auction process.

Unmeasured capital plays a key role in several models. Atkeson and Kehoe (2004) and LSV model exogenously-evolving TFP for each vintage of firms, and they call that TFP organization capital. Brynjolfsson and Yang (2002), Hall (2000), Atkeson and Kehoe (2005), and Laitner and Stolyarov (2003) emphasize the role of unmeasured capital in raising stock prices.

\section{Conclusion}

We have argued that the division of labor and the firm specificity of human capital are driven primarily by the proliferation of technologies. This implies that the size of the rents to a successful match have grown relative to the rents in an average match. Of itself, this implies nothing about the division of those rents. But given how firms actually do form - founders, managers and venture capitalists assemble those assets needed to run the technology at hand - the growth in the rents may largely be appropriated by the owners of the firm and by the managers.

Our model used these ideas to explain the experience of the past 40 years. We argued that product variety has grown over the past 35 years and with it, technological variety. We argued that this had raised the inter-worker dispersion of comparative advantage in using different technologies and in making different products, but that the additional rents went mainly to firms and managers. This in turn explained the secular rise in firms earnings, their Tobin's Qs, and the premium earned by their managers.

\section{References}

[1] Atkeson, Andrew and Patrick J. Kehoe. "Modeling and Measuring Organization Capital." Journal of Political Economy 113, no. 5 (October 2005):1026-1053.

[2] Blanchard, Olivier, "Notes on the Evolution of Profits in the OECD." MIT, October 1996. 
[3] Brynjolfsson, Eric, Lauren Hitt, and Shinkyu Yang, "Intangible Assets: How the Interaction of Information Technology and Organizational Structure Affects Stock Market Valuations." Brookings Papers on Economic Activity 1 (2000): 137-199.

[4] Dagsvik, John, Boyan Jovanovic, and Andrea Shepard. "A Foundation for Three Popular Assumptions in Job-Matching Models." Journal of Labor Economics 3 (October 1985): 403-420.

[5] Diamond, Peter. "Aggregate Demand Management in Search Equilibrium." Journal of Political Economy 90 (October 1982): 881-94.

[6] Frydman, Carola and Raven Saks. "Executive Compensation: A New View from a Long-Term Perspective, 1936-2005." July 2007.

[7] Gabaix, Xavier and Augustin Landier. "Why has CEO Pay Increased so Much?" Quarterly Journal of Economics, forthcoming 2008.

[8] Goldin, Claudia, and Lawrence F. Katz, "The Returns to Skill in the United States Across the Twentieth Century." Working Paper No. 7126, National Bureau of Economic Research, Cambridge, MA (1999).

[9] Hall, Robert E., "The Stock Market and Capital Accumulation." American Economic Review 91, no. 5 (December 2001): 1185-1202.

[10] Hall, Robert E., "e-Capital: The Link between the Labor Market and the Stock Market in the 1990s." Brookings Papers on Economic Activity 2000 (2): 73-118.

[11] Integrated Public Use Microdata Series (IPUMS) Database. Minneapolis, MN: Minnesota Population Center, University of Minnesota, 2007.

[12] Jovanovic, Boyan. "The Diversification of Production." Brookings Papers (Microeconomics) 1 (1993): 197-247.

[13] Jovanovic, Boyan, and Robert Moffitt. "An Estimate of a Sectoral Model of Labor Mobility." Journal of Political Economy 98 (August 1990): 827-852.

[14] Julien, Benoit, John Kennes and Ian King, 2000. "Bidding for Labor." Review of Economic Dynamics 3, no. 4 (October 2000): 619-649.

[15] Kambourov, Gueorgui, and Iourii Manovskii. "Rising Occupational and Industry Mobility in the United States: 1968-1997." International Economic Review 49, no. 1 (February 2008): 41-79.

[16] Kaplan, Steven, and Bernadette Minton, "How has CEO Turnover Changed?" National Bureau of Economic Research Working Paper No. 12465, 2006. 
[17] Kortum, Samuel and Josh Lerner. "What Is Behind the Recent Surge in Patenting?" Research Policy, 1999, 28(1), pp. 1-22.

[18] Laitner, John, and Dmitriy Stolyarov. "Technological Change and the Stock Market." American Economic Review 93, no. 4 (September 2003): 1240-1267.

[19] Lippman, Steven A., and John J. McCall. "Competitive Production and Increases in Risk." American Economic Review 71 (March 1981): 207-11.

[20] Lucas, Robert E. Jr. "On the Size Distribution of Business Firms." Bell Journal 9 (Autumn 1978): 508-23.

[21] Lucier, Chuck, Steven Wheeler and Rolf Habbel. "The Era of the Inclusive Leader." Strategy and Business 47 (Summer 2007) Resilience Report Booz Allen Hamilton. http://www.strategy-business.com/ resiliencereport/resilience/rr00047.

[22] Lustig, Hanno, Chad Syverson and Stijn Van Nieuwerburgh, "IT, Corporate Payouts, and the Growing Inequality in Managerial Compensation." University of Chicago, November 2007.

[23] McGrattan, Ellen, and Edward C. Prescott. "Is the Stock Market Overvalued?" Working Paper No. 8077, National Bureau of Economic Research, Cambridge, MA (2001).

[24] Mincer, Jacob, and Yoshio Higuchi. "Wage Structures and Labor Turnover in the United States and Japan." Journal of the Japanese and International Economy 2 (June 1988): 97-133.

[25] Mitchell, Matthew. "The Scope and Organization of Production: Firm Dynamics over the Learning Curve." RAND Journal of Economics Vol. 31, no. 1 (Spring 2000): 180-205.

[26] Moscarini, Giuseppe, and Francis Vella. "Aggregate Worker Reallocation and Occupational Mobility in the United States: 1971-2000." Yale University, April 2003.

[27] Myerson, Roger. "Optimal Auction Design" Mathematics of Operation Research 6 (1981): 58-73.

[28] Nelson, Daniel. Managers and Workers. 2nd ed. Madison, WI: University of Wisconsin Press, 1995.

[29] Organization for Economic Cooperation and Development. OECD Economic Outlook, 1993, 1997, 1998. 
[30] Prescott, Edward C. and Michael Visscher. "Organization Capital." Journal of Political Economy 88, no. 3 (June 1980): 446-61.

[31] Smith, Adam. An Inquiry into the Nature and Causes of the Wealth of Nations. 1776. Reprint. Edited by Roy H. Campbell and Andrew S. Skinner. Oxford: Clarendon, 1976.

[32] Stewart, Jay. "Recent Trends in Job Stability and Job Security: Evidence from the March CPS." Working Paper no. 356, Bureau of Labor Statistics (March 2002).

[33] United States Bureau of the Census. "The Relationship Between the 1990 Census and Census 2000 Industry and Occupation Classification Systems." Technical Paper \#65 (October 2003).

[34] United States Bureau of the Census, Department of Commerce. Statistical Abstract of the United States. Washington, DC: Government Printing Office, various issues.

[35] United States Bureau of the Census, Department of Commerce. Historical Statistics of the United States, Colonial Times to 1970. Washington, DC: Government Printing Office, 1975.

[36] United States Bureau of Labor Statistics. Monthly Labor Review. Washington, DC: Government Printing Office, various issues.

[37] United States Bureau of Economic Analysis. Survey of Current Business. Washington, DC: Government Printing Office, 2007.

[38] Wright, Steven. "Measures of Stock-Market Value and Returns for the U.S. Nonfinancial Corporate Sector, 1900-2002." Review of Income and Wealth 50, no. 4 (December 2004): 561-85.

\section{Appendix}

Derivation of (21).- Equation (15) reads

$$
A-B m=\frac{1}{\sigma \lambda} m\left(m+1+\frac{\sigma m}{2}-\frac{3 \sigma}{2}\right)
$$

leading to the quadratic

$$
\sigma \lambda A-\sigma \lambda B m=m^{2}\left(1+\frac{\sigma}{2}\right)+\left(1-\frac{3 \sigma}{2}\right) m
$$


i.e.,

$$
m^{2}\left(1+\frac{\sigma}{2}\right)+\left(1-\frac{3 \sigma}{2}+\sigma \lambda B\right) m-\sigma \lambda A=0
$$

leading to (21).

Approximating (21). - When $\lambda$ is small, we can expand this linearly around $\lambda=0$ to get

$$
\begin{aligned}
m & =\frac{1}{2+\sigma} \frac{1}{2}\left(1-\frac{3 \sigma}{2}\right)^{-1}\left(2 B\left(1-\frac{3 \sigma}{2}\right)+(4+2 \sigma)\right) \sigma \lambda \\
& =\frac{1}{2+\sigma}\left[B+\left(1-\frac{3 \sigma}{2}\right)^{-1}(2+\sigma)\right] \sigma \lambda \\
& =\left[B+\left(1-\frac{3 \sigma}{2}\right)^{-1}\right] \sigma \lambda=\left(B+\frac{2}{2-3 \sigma}\right) \sigma \lambda
\end{aligned}
$$

which is increasing in $\sigma$. 